negative curvature; the controls showing $179^{\circ}$ positive and $115^{\circ}$ negative curvature. Comparison experiments using synthetic $\beta$ indole-acetic acid in a similar concentration, with 40 coleoptile pairs, gave $182^{\circ}$ positive curvature and $14^{\circ}$ negative curvature. Water controls gave $25^{\circ}$ positive and $23^{\circ}$ negative curvature.

These experiments suggest that skatole may act in the plant as a growth-promoting hormone. Both skatole and $\beta$ indole-acetic acid were observed to be markedly light-sensitive.

Department of Botany,
Queen's University,

J. Glover.

Belfast.

Jan. 17.

${ }^{1}$ NATURE, 135, 101 (1935).

\section{Reported Occurrence of European Fishes on the Tavoy Coast, Burma}

IN a letter published in NATURE of January $25^{1}$, Dr. Hora and Dr. Mukerji record the supposed occurrence of five European fishes on the Tavoy coast, Burma. The specimens were sent to me for examination, and I am able to confirm the identifications, but, as I have already pointed out in correspondence with Dr. Hora, I am of the opinion that the specimens did not come from the coast of Burma. The species in question are found in the North Atlantic, and some in the Mediterranean also, but none has ever been found in tropical seas. Without attempting to explain the manner in which the mistake has occurred, I can only reaffirm my conviction that the supposed occurrence of such fishes as Cottus bubalis and Ammodytes lanceolatus on the cosst of Burma is so widely opposed to all the known facts of geographical distribution as scarcely to merit serious consideration.

Department of Zoology (Fishes),

British Museum (Natural History), London, S.W.7.

${ }^{2}$ NATURE, 137, $152(1936)$.

\section{Fossil Pollen in Scottish Tertiary Coals}

THe application of Raistrick's method ${ }^{1}$ of extract. ing microspores from Carboniferous coals to lignites of Tertiary age from Mull and Morvern, Argyllshire, has revealed that these inferior coals are rich in pollen in a good state of preservation.

The examination of the material is now in progress, and it is hoped to publish a detailed report shortly. In the meantime, it may be of interest to record that forms closely resembling the following modern types are present: Ginkgo, Abies, Cedrus, Pinus and Podocarpus of the gymnosperms, and Alnus, Engelhardia, Hamamelidacece (several genera), Magnolia, Planera and Smilax of the angiosperms.

Spores of non-flowering plants do not seem to be present in great numbers or variety.

Geological Survey of Great Britain, J. B. Simpson.

19 Grange Terrace, Edinburgh.

Jan. 21.

'Raistrick, Trans. Inst. Min. Eng., 88, 142 (1934).

\section{Recent Research on Cancer}

IN the correspondence columns in NATURE of January 18, Prof. Passey criticises a statement in the editorial of the twelfth annual report of the British Empire Cancer Campaign for which I am responsible. Although the point at issue must, I think, strike any impartial observer as of a rather hair-splitting character, and scarcely worthy of notice, I feel that the exact facts should be placed before readers of NATURE.

The actual statement made by Prof. Passey in his report was as follows: "We feel we are on safe ground when we say that given a full mixed diet, infestation with the parasite Gongylonema neoplasticum induces no changes other than perhaps an occasional trivial hyperkeratosis of the squamous epithelium-certainly there is no papillomatosis and nothing resembling malignant discase". The editorial statement was as follows: ". . . the experiments appear to show that, provided the rats are fed on a correct diet, cancer does not develop as a result of this parasitic infection".

I entirely fail to see why my statement in the editorial should be any more misleading than Prof. Passey's original one, and the writer of the article in NATURE is surely as entitled to infer" that "diet may infuence the occurrence of malignant disease" from Prof. Passey's original statement as from my editorial.

While I shall always welcome any legitimate criticism, I feel that in the present instance if there was any ambiguous statement which lent itself to a false inference, it was in Prof. Passey's original report and not in my editorial.

J. P. Lockhart-Mummery.

(Hon. Secretary and Editor, Annual Report, British Empire Cancer Campaign.)

THE paragraph which Mr. Lockhart-Mummery quotes from his own editorial is practically a paraphrase of the words used by Prof. Passey in his report, and as such does not appear open to criticism. But the paragraph in question deals with the negative side only of the matter, and hence might give a misleading impression to the reader. Prof. Passey's experiments upon the combined effect of deficient diet, and the presence of the parasite, have given negative results, but the original positive results of Fibiger cannot be disregarded until adequate reasons are given for their rejection.

The Writer of the Article in "Nature".

\section{Oscillations in Magnetrons}

Is the course of an investigation of the production of oscillations by magnetrons, I have had occasion to determine the impedance of these valves at high frequencies. The valve used in the experiments was of the split-anode type, and the impedance between the two anode segments was resolved into that of an effective capacitance in parallel with a resistance.

The variation with magnetic field intensity of the capacitance component obtained at wave-lengths of 20,30 and 40 metres is given by the three curves in Fig. 1. Over the dotted portions of each curve oscillations were produced at the wave-length used in determining the curve. It will be seen that in the neighbourhood of oscillation the valve capacitance underwent considerable change, which was of such magnitude that in the region of minimum valve 